\title{
AN INVESTIGATION OF IGBT OPEN GATE FAULT ON FIELD ORIENTED CONTROL OF INDUCTION MOTOR DRIVE SYSTEM
}

\author{
Elbarbary, Zakaria Mohamed Salem \\ Department of Electrical Engineering, Faculty of \\ engineering \\ Kafrelsheikh University, Egypt King Khalid University, \\ Faculty of engineering \\ Saudi Arabia Tanta, Egypt \\ z_elbarbary@yahoo.com
}

\author{
Mahmoud Mohamed Elkholy \\ Department of Electrical Engineering, Faculty of \\ engineering \\ Zagazig University, Egypt Zagazig, Egypt King Khalid \\ University, Faculty of engineering \\ Saudi Arabia \\ Melkholy2007@yahoo.com
}

\begin{abstract}
This paper introduces a performance analysis of indirect rotor field oriented control of three phase induction motor drive system under one IGBT open gate fault of the inverter. The performance characteristics of the drive are investigated under healthy operating condition and at faulty condition with IGBT of upper phase leg is opened. The Total Harmonic Distortion of phases current in case opened IGBT are derived. The Simulation of the case study is carried out by using the Matlab/Simulink package on $1.1 \mathrm{~kW}, 220 / 380 \mathrm{~V}, 50 \mathrm{~Hz}$ three phase induction motor.
\end{abstract}

Keywords-Induction Motor Drive, Current control Voltage Source Inverter (CCVSI), Three Phase Inverter (FSTPI), Insulated Gate Bipolar Transistor (IGBT)

\section{INTRODUCTION}

Induction motors satisfy the production needs of most industrial processes. It used not only for general purposes, but also in hazardous locations and severe environments. These industrial applications include machine tools, conveyors, pumps, centrifugal machines, presses, elevators and packaging equipment [1-3]. The other type of applications in hazardous locations include petrochemical and natural gas plants. The energization of such motors in these processes and applications can be achieved through the following ways: (1) direct on-the-line starting, (2) soft-starting and (3) Adjustable-Speed Drive (ASD) control. With the development of power electronics and digital signal processor, induction motors are predominantly fed from Pulse Width Modulation (PWM) inverter, so, ASDs are widely adopted in many industrial applications. In fact, the main reasons for their adoption in these applications are owed to the robust control and high performance quality that ASDs offer as compared to soft starters. Nevertheless, using soft starters for reducing high starting currents is a low cost means in comparison to modern ASDs if speed-torque control is not required. The faults sources in the drives are, the power converter circuits (about $38 \%$ ), control circuits (about 53\%) and external auxiliaries (about 9\%) [4-6].There two types of power semiconductor switches' faults of inverters. The first type is transistor short-circuit switch-fault, this fault leads to catastrophic failure of the inverter if the other transistor of the same inverter leg is turned-on, this resulting in a direct short-circuit of the dc-bus link. To prevent the short circuit fault, it is necessary to minimize possible elapsed time after the fault occurred [7-11,18]. The other type of faults is open circuit fault of transistor. It is commonly due to either a malfunction in one of the PWM output ports of the controller that is transmitting the switching patterns, or sequences to the transistors, or a malfunction in the gate drive. The drive may be operating with open circuit fault of any transistor, but with much inferior of performance, the electromechanical torque is affected and pulsating because the motor currents are asymmetric due to one phase's current is unipolar. Hence, a drive fault diagnostic system determines the type; hence the fault tolerant takes appropriate correction action of the fault. There are two ways to test the drive fault, experimentally in the actual motor drives and another is fault simulation[12-16].

In this study, a closer look at the effects of one switch open gate fault of inverter on machine performance is carried out. A simulation results are carried out using Matlab/Simulink package.

\section{SYSTEM DESCRIPTION}

The proposed system intended for performance analysis of indirect rotor field oriented control of induction motor drive is shown in Fig. 1.this section presents the mathematical model of the induction motor drive system to revise the recital of the scheme at diverse working settings. In addition detailed analyses of open gate fault of inverter.

\subsection{INDIRECT ROTOR FIELD ORIENTED CONTROL}

The Field Oriented Control (FOC) block receives the torque command $\mathrm{T}^{*}$ obtained from the speed controller while the flux command $\lambda_{\mathrm{dr}}^{*}$ is maintained constant. The field 
oriented control block performs the slip calculation and generates the current command components $\mathrm{i}_{\mathrm{qs}}^{\mathrm{e}}$ and $\mathrm{i}_{\mathrm{ds}}^{\mathrm{e}}$ in a rotating reference frame. These components are further manipulated by axes transformations to obtain the abc current command components ia, ib and ic. The axes transformations used for the present system are expressed as follows:

$\left[\begin{array}{c}\mathrm{i}_{\mathrm{qs}}^{\mathrm{s}^{*}} \\ \mathrm{i}_{\mathrm{ds}}^{\mathrm{s}^{*}}\end{array}\right]=\left[\begin{array}{cc}\cos \theta_{\mathrm{s}} & \sin \theta_{\mathrm{s}} \\ \sin \theta_{\mathrm{s}} & \cos \theta_{\mathrm{s}}\end{array}\right] *\left[\begin{array}{c}\mathrm{i}_{\mathrm{qs}}^{*} \\ \mathrm{i}_{\mathrm{ds}}^{\mathrm{e}^{*}}\end{array}\right]$

where, $\theta_{\mathrm{s}}$ represents the sum of the slip and rotor angles:

$$
\mathrm{qds} \rightarrow \mathrm{abc}\left\{\begin{array}{l}
\mathrm{i}_{\mathrm{as}}^{\mathrm{s}^{*}}=\mathrm{i}_{\mathrm{qs}}^{\mathrm{s}^{*}} \\
\mathrm{i}_{\mathrm{bs}}^{\mathrm{s}^{*}}=-\frac{1}{2} \mathrm{i}_{\mathrm{qs}}^{\mathrm{s}^{*}}-\frac{\sqrt{3}}{2} \mathrm{i}_{\mathrm{ds}}^{\mathrm{s}^{*}} \\
\mathrm{i}_{\mathrm{cs}}^{\mathrm{s}^{*}}=-\frac{1}{2} \mathrm{i}_{\mathrm{qs}}^{\mathrm{s}^{*}}+\frac{\sqrt{3}}{2} \mathrm{i}_{\mathrm{ds}}^{\mathrm{s}^{*}}
\end{array}\right\}
$$

\subsection{CURRENT CONTRol Voltage SOURCE INVERTER}

A three-phase inverter consists of a six switch (S1 to S6) inverter. The DC link capacitor fed from three phase uncontrolled rectifier The two- level current control of the sixswitch bridge inverter used to control the load current by forcing it to follow a reference one. This is achieved by the switching action of the inverter to keep the current within the hysteresis band. The load currents are sensed and compared with respective command currents using two independent hysteresis comparators. The output signal of the comparators are used to activate the inverter power switches. This controller is simple and provides excellent dynamic performance:

$\mathrm{i}_{\text {ref }}=\mathrm{i}_{\max } \sin (\omega \mathrm{t})$

$\mathrm{i}_{\text {up }}=\mathrm{i}_{\text {ref }}+\mathrm{H}$

$\mathrm{i}_{\mathrm{lo}}=\mathrm{i}_{\mathrm{ref}}-\mathrm{H}$

Where:

$\mathrm{I}_{\text {ref }}=$ The reference current (may be $\mathrm{i}_{\mathrm{ar}}, \mathrm{i}_{\mathrm{br}}$ or $\mathrm{i}_{\mathrm{cr}}$ )

$\mathrm{I}_{\mathrm{up}}=$ The upper band, ilo is the lower band and

$\mathrm{H}=$ The hysteresis band

For $\mathrm{i}_{\mathrm{ar}}>0$ : if $\mathrm{i}_{\mathrm{a}}>\mathrm{i}_{\mathrm{up}}$ then $\mathrm{NA}=0$, this means that the inverter output voltage switches to negative in order to reduce the line current. In the same manner if $\mathrm{i}_{\mathrm{a}}<\mathrm{i}_{\mathrm{lo}}$, then. $\mathrm{NA}=1$, where the inverter output voltage switches to positive in order to increase the line current. The same sequence is followed for phase $b$ and c. Where, NA1, NB1 and NC1 are complementary of NA $\mathrm{NB}$ and NC, respectively. The modulated phases voltages of six switch inverter are introduced as a function of switching logic NA, NA1, NB, NB NC and NC1 of power switches by the following relations:

$\left[\begin{array}{l}\mathrm{V}_{\mathrm{a}} \\ \mathrm{V}_{\mathrm{b}} \\ \mathrm{V}_{\mathrm{c}}\end{array}\right]=\frac{\mathrm{V}_{\mathrm{dc}}}{3}\left[\begin{array}{ccc}2 & -1 & -1 \\ -1 & 2 & -1 \\ -1 & -1 & 2\end{array}\right]\left[\begin{array}{c}\mathrm{NA} \\ \mathrm{NB} \\ \mathrm{NC}\end{array}\right]$

\subsection{INDUCTION MOTOR MODEL}

Squirrel-cage induction motor is represented in its $d-q$ dynamic model. This model represented in synchronous reference frame is expressed as follows:

$\left[\begin{array}{c}\mathrm{V}_{\mathrm{qse}}^{\mathrm{e}} \\ \mathrm{V}_{\mathrm{dse}}^{\mathrm{e}} \\ 0 \\ 0\end{array}\right]=\left[\begin{array}{cccc}\mathrm{R}_{\mathrm{s}}+\mathrm{pL}_{\sigma} & \omega_{\mathrm{e}} \mathrm{L}_{\sigma} & \mathrm{p} \frac{\mathrm{L}_{\mathrm{m}}}{\mathrm{L}_{\mathrm{r}}} & \omega_{\mathrm{e}} \frac{\mathrm{L}_{\mathrm{m}}}{\mathrm{L}_{\mathrm{r}}} \\ -\omega_{\mathrm{e}} \mathrm{L}_{\sigma} & \mathrm{R}_{\mathrm{s}}+\mathrm{pL}_{\sigma} & -\omega_{\mathrm{e}} \frac{\mathrm{L}_{\mathrm{m}}}{\mathrm{L}_{\mathrm{r}}} & \mathrm{p} \frac{\mathrm{L}_{\mathrm{m}}}{\mathrm{L}_{\mathrm{r}}} \\ -\mathrm{R}_{\mathrm{r}} \mathrm{L}_{\mathrm{m}} & 0 & \mathrm{R}_{\mathrm{r}}+\mathrm{pL}_{\sigma} & \left(\omega_{\mathrm{e}}\right. \\ & & \left.-\omega_{\mathrm{r}}\right) \mathrm{L}_{\mathrm{m}} \\ 0 & -\mathrm{R}_{\mathrm{r}} \mathrm{L}_{\mathrm{m}} & -\left(\omega_{\mathrm{e}}\right. & \mathrm{R}_{\mathrm{r}} \\ & \left.-\omega_{\mathrm{r}}\right) \mathrm{L}_{\mathrm{m}} & +\mathrm{pL} \mathrm{L}_{\sigma}\end{array}\right]\left[\begin{array}{c}\mathrm{I}_{\mathrm{qs}}^{\mathrm{e}} \\ \mathrm{I}_{\mathrm{ds}}^{\mathrm{e}} \\ \lambda_{\mathrm{qr}}^{\mathrm{e}} \\ \lambda_{\mathrm{dr}}^{\mathrm{e}}\end{array}\right]$

The electromechanical equation is also given by:

$T_{e}-T_{L}=J \frac{d \omega_{r}}{d t}+B \omega_{r}$

where, the electromagnetic torque is expressed as:

$\mathrm{T}_{\mathrm{e}}=\frac{3}{2} \frac{\mathrm{p}}{2} \cdot \frac{\mathrm{L}_{\mathrm{m}}}{\mathrm{L}_{\mathrm{r}}}\left(\mathrm{I}_{\mathrm{qs}}^{\mathrm{e}} \lambda_{\mathrm{dr}}^{\mathrm{e}}-\mathrm{I}_{\mathrm{ds}}^{\mathrm{e}} \lambda_{\mathrm{qr}}^{\mathrm{e}}\right)$

Equation (9) denotes that the torque can initially proportional to the quadrature component of the stator current $\left(\mathrm{I}_{\mathrm{qs}}^{*}\right)$ if the qe-axis component of the rotor flux becomes zero (de-axis is aligned with the rotor flux axis) and the de-axis component $\left(\lambda_{\mathrm{dr}}^{* \mathrm{e}}\right)$ is kept constant. This is the philosophy of the vector control technique. In accordance, Equatuib (9) is linearized as:

$\mathrm{T}_{\mathrm{e}}=\mathrm{K}_{\mathrm{t}}\left|\lambda_{\mathrm{dr}}^{*}\right| \mathrm{I}_{\mathrm{qs}}$

This equation is similar to that of the separately excited dc motor. The angular slip frequency command $\left(\omega_{\mathrm{sl}}^{*}\right)$ is calculated as follow:

$\omega_{\mathrm{sI}}^{*}=\frac{\mathrm{L}_{\mathrm{m}}}{\tau_{\mathrm{T}}^{*}} \frac{\mathrm{I}_{\mathrm{qs}}^{\mathrm{e}^{*}}}{\lambda_{\mathrm{dr}}^{\mathrm{e}^{*}}}$
$\mathrm{I}_{\mathrm{ds}}^{\mathrm{e}^{*}}=\frac{1}{\mathrm{~L}_{\mathrm{m}}}\left(1+\tau_{\mathrm{r}}^{*} \mathrm{p}\right) \lambda_{\mathrm{dr}}^{\mathrm{e}^{*}}$ 
The angular frequesncy is obtained as follows:

$\omega_{\mathrm{e}}=\omega_{\mathrm{r}}+\omega_{\mathrm{sl}}$

$\theta_{\mathrm{e}}=\int \omega_{\mathrm{e}} \cdot \mathrm{dt}$ from:

The torque producing current component is calculated

$$
\mathrm{I}_{\mathrm{qs}}^{\mathrm{e}^{*}}=\frac{1}{\mathrm{k}_{\mathrm{t}}} \frac{\left(\omega_{\mathrm{r}}^{* 0}-\omega_{\mathrm{r}}\right)}{\lambda_{\mathrm{dr}}^{\mathrm{e}^{*}}} \frac{\mathrm{K}_{\mathrm{ps}}\left[1+\tau_{\mathrm{cs}} \mathrm{S}\right]}{\tau_{\mathrm{cs}} \mathrm{S}}
$$

where, $\omega_{\mathrm{r}}$ is the motor speed.

Where,

$$
\begin{aligned}
& \mathbf{L}_{\boldsymbol{\sigma}}=\mathbf{L}_{\mathbf{s}}-\frac{\mathbf{L}_{\mathbf{m}}^{2}}{\mathbf{L}_{\mathbf{r}}} \\
& \sigma=1-\frac{\mathrm{L}_{\mathrm{m}}^{2}}{\mathrm{~L}_{\mathrm{s}} \mathrm{L}_{\mathrm{r}}}
\end{aligned}
$$$$
\mathrm{T}_{\mathrm{r}}=\frac{\mathrm{L}_{\mathrm{r}}}{\mathrm{R}_{\mathrm{r}}}
$$

$\mathrm{V}_{\mathrm{qs}}{ }^{\mathrm{e}}, \mathrm{V}_{\mathrm{ds}}{ }^{\mathrm{e}}$

$\mathrm{I}_{\mathrm{qs}}^{\mathrm{e}}, \mathrm{I}_{\mathrm{ds}}^{\mathrm{e}}$

$\lambda_{\mathrm{qs}}^{\mathrm{e}}, \lambda_{\mathrm{ds}}^{\mathrm{e}}$

$\mathrm{R}_{\mathrm{s}}, \mathrm{R}_{\mathrm{r}}$

qe-de -axis stator voltage

qe-de -axis stator current

qe-de -axis stator flux linkage

$\mathrm{J}, \mathrm{B}$ Moment of inertia and viscous friction coefficients

$\mathrm{L}_{\mathrm{s}}, \mathrm{L}_{\mathrm{r}}, \mathrm{L}_{\mathrm{m}} \quad$ Stator, rotor and mutual inductances

$\mathrm{T}_{\mathrm{e}}, \mathrm{T}_{\mathrm{L}} \quad$ Electromagnetic and load torque

$\mathrm{K}_{\mathrm{t}}=\frac{3 \mathrm{p}}{2} \frac{\mathrm{p}}{2} \frac{\mathrm{L}_{\mathrm{m}}}{\mathrm{L}_{\mathrm{r}}} \quad$ Torque constant

\subsection{OPEN-GATE SWITCH FAULT}

Failure in either one of the PWM digital output ports of a controller board or one of the isolation amplifiers of the gate drive can lead to an open-circuit fault in the transistor switch, as shown in Fig. 2. A transistor open-circuit switch fault is a less severe type of fault as compared to the short-circuit switch fault. Nevertheless, such type of inverter fault will still generate disturbances in the form of pulsating electromagnetic torque and a substantial dc component in the stator winding currents.

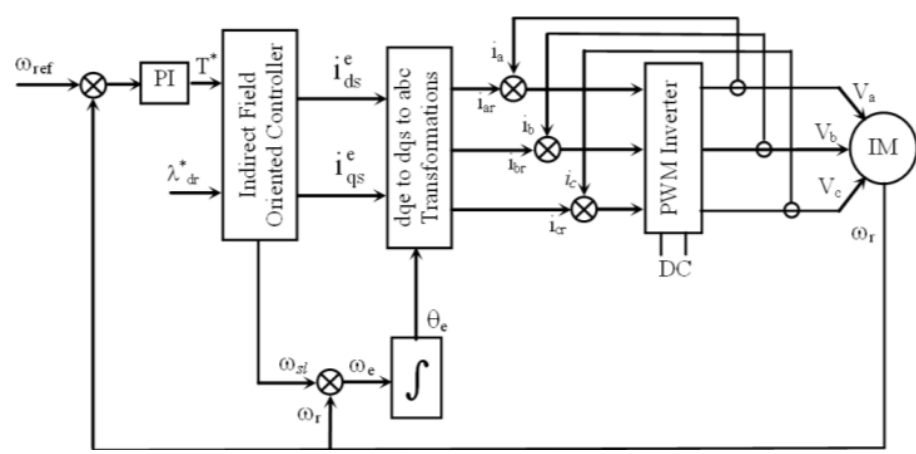

Fig. 1. Block diagram of the proposed system

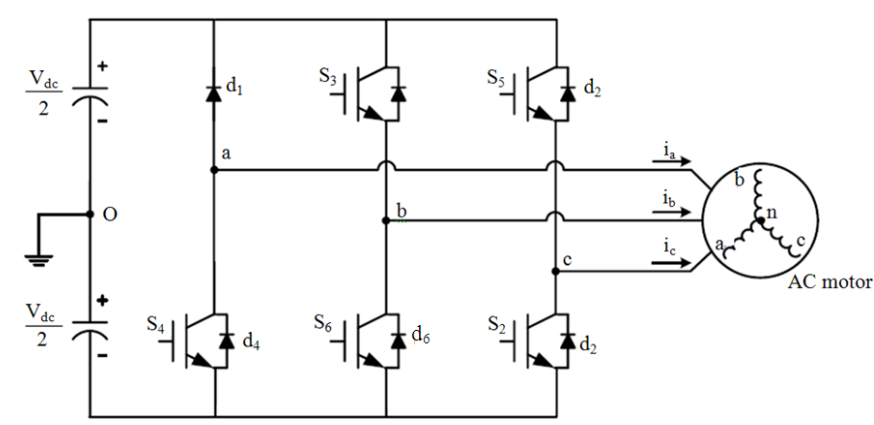

Fig. 2. Three- phase inverter with one switch open

This dc current component will cause thermal problems, such as temperature rise, in the windings. Eventually, insulation breakdown will occur if the fault is left unmitigated. For the sake of analysis, an open-circuit fault occurring in switch, S1, is considered in this study. A misfiring of the transistor switch, S1, will result in an inverter circuit topology, as illustrated in Fig. 2. Intuitively, through the observation of Fig. 2 one can state that there will not be any positive current flow into the motor for phase-a after the fault occurrence, due to the absence or malfunction of switch S1. Hence, the resulting post-fault phase-a current, Ia , will consist of a dc (unidirectional) current component. If the motor has an isolated (floating) neutral connection, this dc (unidirectional) current term will be divided between the currents of the remaining two phases. The consequence of dc (unidirectional) current in the motor windings leads to the significant presence of motor torque pulsations.

In this section interdues the performance analysis of field oriented three phase induction motor. There are in two case of operation with the load torque is changed from no load to 3 N.m at $0.6 \mathrm{sec}$. The first case is the healthy operation of the drive with six IGBT. The second case is the operation of the drive with IGBT connected to the upper arm of the bridge which connected to the phase (a) of the motor is opened. The system shown in figure (1) with the help of equations (1) to equation (15) is simulated using the SIMULINK toolbox of the MATLAB to analysis of the drive. [17]. Table (1) contain the motor parameters used in simulation. Table (1) Induction Motor Parameters: 
Rated power

$1.1 \mathrm{~kW}$

No. of poles

4

Stator resistance

$7.4826 \mathrm{ohm}$

Referred rotor resistance

$3.6840 \mathrm{ohm}$

Referred rotor leakage inductance

$0.0221 \mathrm{H}$

Stator leakage inductance

$0.0221 \mathrm{H}$

Mutual inductance

$0.4114 \mathrm{H}$

Motor frequency

$50 \mathrm{~Hz}$

Rated voltage

$220 / 380$ volts

Inertia

$0.02 \mathrm{~kg} \cdot \mathrm{m} 2$

\section{RESULTS AND DISCUSSION}

The stator currents of the motor with healthy opeartion are balanced and do not have any DC component as shown in Fig. 3. Figure 4-6 show the variation of stator currents and DC component when the IGBT opened. In this case, the motor currents are unbalanced and current of phase (a) has a negative DC component but phases (b) and (c) have a DC component with opposite direction as shown in Fig. 7.

The motor current in case of opened IGBT is higher than vaules of motor current in healthy condition. Therefore, the motor cannot be loaded with full load to prevent overheating as shown Fig. 8. Table 2 show the variation of Total Harmonic Distortion (THD) of phases currents (a), (b) and (c) in faulty case and at different values of load torque.

Then the THD of healthy phases is higher than THD of Opened IGBT. When load torque changed from no load to 3 N.m the motor speed response in case of IGBT opened is slower than its response in healthy opeation as shown in Fig. 9. The ripple in motor speed in case of IGBT opened is higher than speed ripple of healthy opearion due to increase torque ripple as shown in Fig. 10. The d-axis component of rotor flux linkage in case IGBT opened is lower than one of healthy operation as shown in Fig. 11. In healthy operation the q axis component of rotor flux is zero. Therefore the field orientation is achieved. But, In case of one IGBT opened, The q- axis component has a ripple and the value close to zero an shown in Fig. 12, so that the ripples in motor speed and torque are increased.

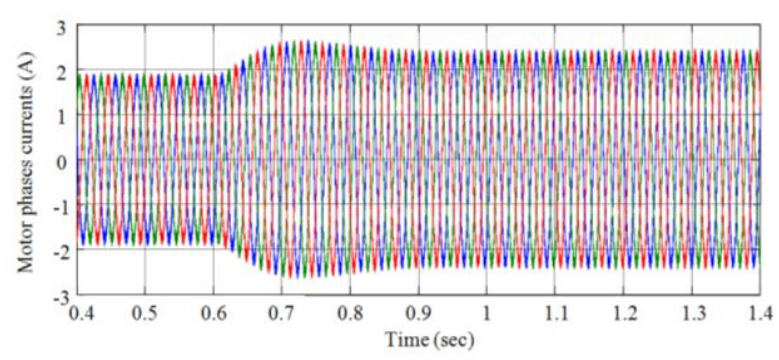

Fig. 3. Variation of stator currents (Healthy Operation)

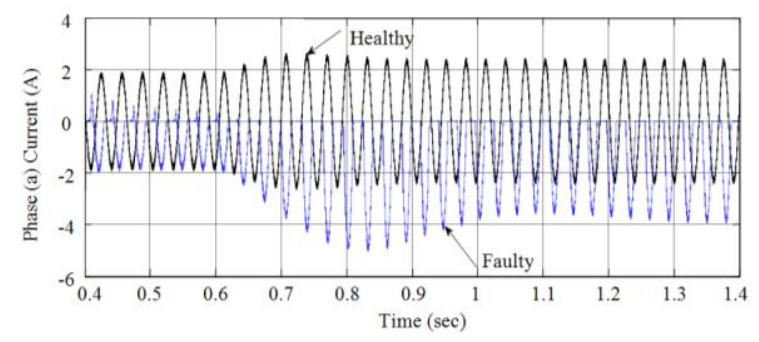

Fig. 4. Variation of motor phase (a) current with time

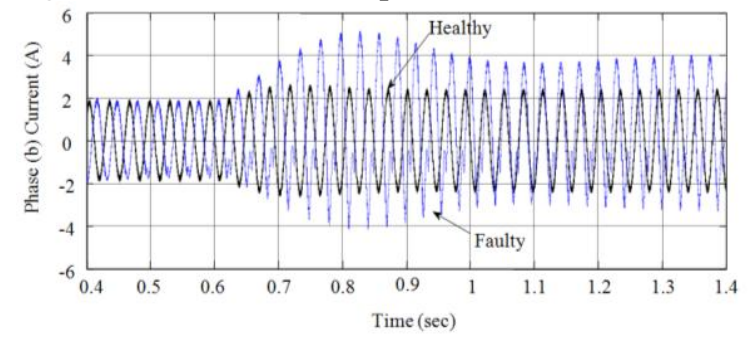

Fig. 5. Variation of motor phase (b) current with time

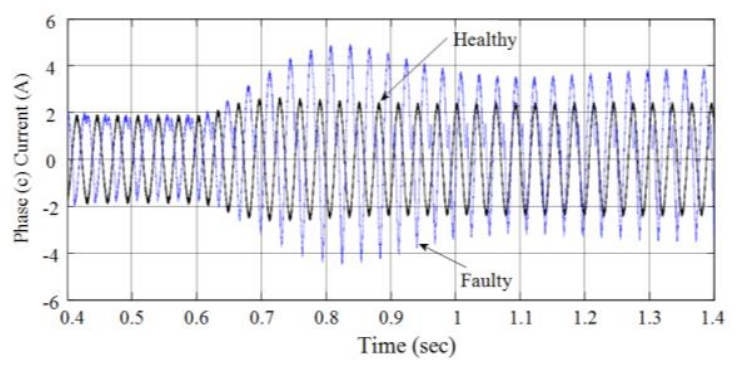

Fig. 6. Variation of motor phase (c) current with time

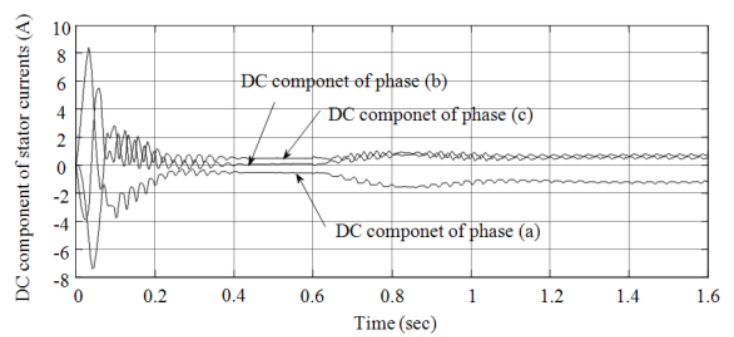

Fig. 7. Variation of DC component of motor phases currents (Faulty Operation) 


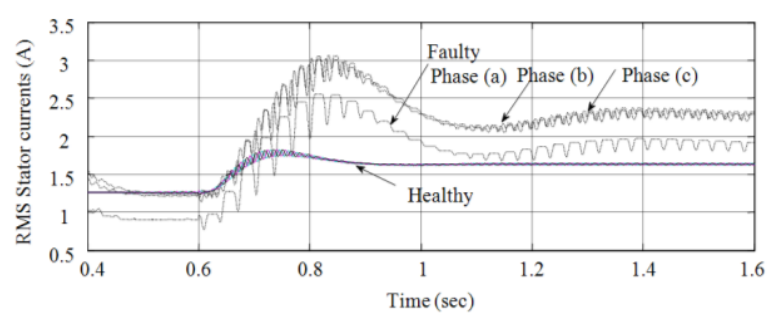

Fig. 8. Variation of RMS of motor phases currents (Faulty Operation)

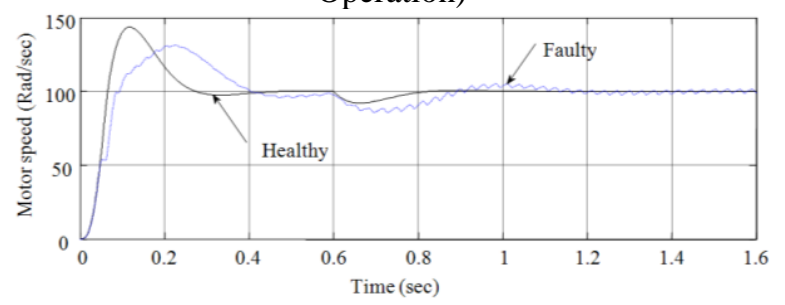

FIG. 9. VARIATION OF MOTOR SPEED WITH TIME

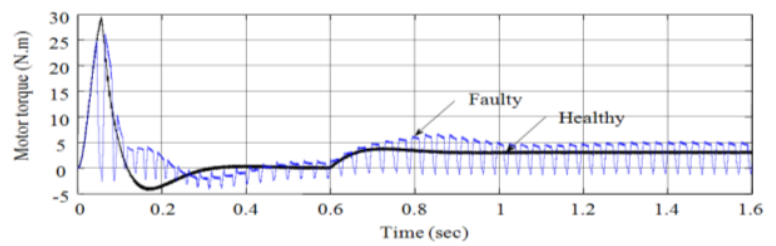

Fig. 10. Variation of motor torque with time

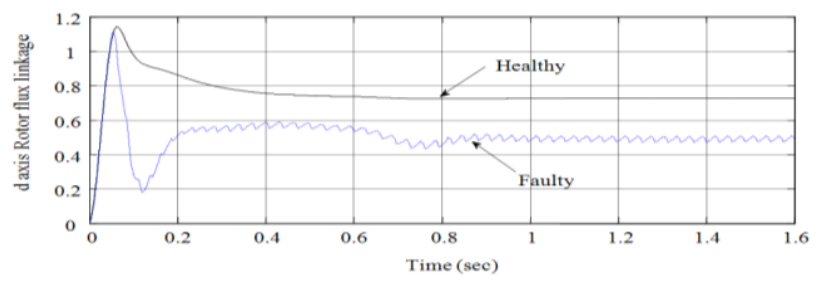

Fig. 11. Variation of d-axis component of rotor flux linkage

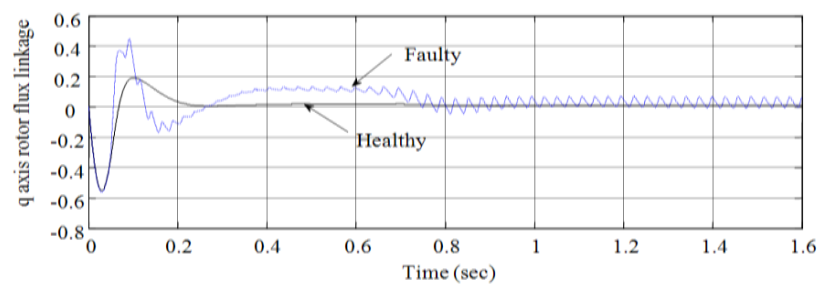

Fig. 12. Variation of q-axis component of rotor flux linkage with time

Table 2. Variation of THD of phases currents at faulty operation

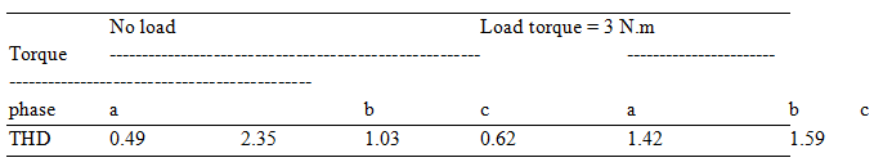

\section{CONCLUSION}

The performance characteristics of IRFO control of 3phase induction motor drive when one IGBT of 3- phase inverter is opened has been investigated. The current of phase which is is connected to open IGBT has a DC offset component and the other phases have half DC offset component with opposite direction. The THD of healthy phases is higher than THD of opened IGBT. In case of Opened IGBT the motor load must be lower than rated value to prevent overheating. The motor ripples in speed and torque increase with opened IGBT and this leads to increase the motor noise. The motor response to load variation is decreased with failure of one IGBT. The q-axis component of rotor flux linkage has a ripple and close to zero.

\section{REFERENCES}

[1] Mahmoud M. Gaballah "Design and Implementation of Space Vector PWM Inverter Based on a Low Cost Microcontroller". Arab journal of Sience Engineering. 2012

[2] Channegowda, P.; John, V.: Filter optimization for grid interactive voltage source inverter. IEEE Trans. Ind. Electron. 157, 41064114(2010)

[3] Khalaf Salloum Gaeid "Fault Tolerant Control of Induction Motor" Modern Applied Science Vol. 5, No. 4; August 2011

[4] Abramik, S., W. Sleszynski, J. Nicrnanski and H. Piquet, 2003. A diagnostic method fir \&-line foul1 detection and localizarion in VSI-FED ac driver. Proceedings of the 10th Europcan Confercncc on Powcr Electronicsand Applicatians.Toulousc, France. CD-ROM paper

[5] Benbouzid, M.E.H., 2005. A loss-minimization DTC scheme for EV induction motors. Proc. IEEE VPPC, Chicago, IL, pp: 315 321.

[6] Benbouzid, M.E.H., D. Diallo and M. Zeraoulia, 2007. Advanced fault tolerant control of induction-motor drives for $\mathrm{EV} / \mathrm{HEV}$ traction applications: From conventional to modern and intelligent control techniques. IEEE Trans. Vehicular Technol., 56.

[7] Chan, C.C., 2002. The state of the art of electric and hybrid vehicles. Proc. IEEE, 90: 247-275. DOI: 10.1109/5.989873

[8] Chokhawala, R.S., J. Catt and L. Kiraly, 1995. A discussion on IGBT short-circuit behavior and fault protection schemes. IEEE Trans. Industry Applications, 31: 256-263. DOI: 10.1109/28.370271

[9] Eason, G., B. Noble and I.N. Sneddon, 1995. On certain integrals of Lipschitz-Hankel type involving products of Bessel functions. Phil. Trans. Roy. Soc. London, A247: 529-551.

[10] Gerada, C., M. Sumner and J. Arellano-Padilla, 2008. Investigation of induction machine phase open circuit faults using a simplified equivalent circuit model. Electrical. And Electron. Eng., Univ. of Nottingham,

[11] Mendes, A.M.S., X.M. Lopez-Fernandez and A.J.M. Cardoso, 2007. Thermal behavior of a three-phase induction motor fed by a fault-tolerant voltage source inverter. IEEE Trans. Industry Applications, 43: 724-730.

[12] Monfared, M., H. Rastegar and H.M. Kojabadi, 2008. Overview of modulation techniques for the four-switch converter topology. PECon 08, 1-3 Dec 2008, Johor Baharu, Malaysia. 
Recent Innovations in Mechatronics (RIiM) Vol. 1. (2014). No. 1-2.

DOI: $10.17667 /$ riim.2014.1-2/3.

[13] Spee, R. and A.K. Wallace, 1990. Remedial strategies for brushless dc drive failures. IEEE Trans. Industry Applications, 26: 259-266. DOI: 10.1109/28.54251

[14] Husi G; Szász C; Chindris V Artificial Immune System Implementation upon Embryonic Machine for Hardware Faulttolerant Industrial Control Applications Journal Of Computer Science And Technology (ISSN: 1000-9000) 10: (4) pp. 60-66. (2010)

[15] Welchko, B.A., J. Wai, T.M. Jahns and T.A. Lipo, 2006. Magnetflux-nulling control of interior PM machine drives for improved steady-state response to short-circuit faults. IEEE Trans. Industry Applications, 42: 113-120.
[16] Welchko, B.A., T.A. Lipo, T.M. Jahns and S.E. Schulz, 2004. Fault tolerant three-phase AC motor drive topologies: A comparison of features, cost and limitations. IEEE Trans. Power Electronics., 19.

[17] Matlab/Simulink Toolbox User's Guide, The Mathworks Inc., Natick, MA, USA, May 1998.

[18] Husi Géza; Darai Gyula: Improving Education Quality By Using High Technology Devices 14th Building Services, Mechanical and Building Industry Days. 462 p.Debrecen, Magyarország, 2008.10.30-2008.10 